\title{
Production of Al-based composite materials including stress-luminescent particles using 3-dimensional penetration casting (3DPC)
}

\author{
Seungwon Lee ${ }^{1}$, Yuta Kusunoki ${ }^{2}$, Naoto Nakamura ${ }^{2}$, Kenji Matsuda ${ }^{1, a}$, Yuukou Horita ${ }^{1}$, Takahisa Ohji ${ }^{1}$, Kenji Amei ${ }^{1}$, Keiji \\ Shibata ${ }^{1}$ and Koji Okino ${ }^{1}$ \\ ${ }^{1}$ Graduate School of Science and Engineering for Research, University of Toyama,3190, Gofuku, Toyama, Toyama, 930-8555, Japan \\ ${ }^{2}$ Graduate School of Science and Engineering for Research, University of Toyama,3190, Gofuku, Toyama, Toyama, 930-8555, Japan
}

\begin{abstract}
A stress-luminescent powder can be applied as sensors because of luminous characteristic under stress. Key point in fabrication is how uniformly to disperse powders in metallic matrix. Three-dimensional penetration casting (3DPC) process is a good application to fabricate the composite materials using stress-luminescent powders and molten Al. A commercial stress-luminescent powder was prepared (a)stress- luminescent powders (Taikourozai Co.) and (b)EZ bright (EZ bright Cooperation). 3DPC process was conducted using a special mould has dimensions of $42 \mathrm{~mm}$ height and $30 \mathrm{~mm}$ diameter. Mould was heated up to $750^{\circ} \mathrm{C}$ before 3DPC. After 3DPC, particles were well dispersed in Al matrix without crack generations with optical microscopy observation. Also, samples were emitted when they were pressed and scratched.
\end{abstract}

\section{Introduction}

A highly-developed material civilization needs more buildings and structures for comfortable living. However, it is getting difficult to maintain and protect buildings and structures from natural disasters, specially, earthquake due to their size and complexity of exterior. The real-time monitoring of stress using sensors can be solution. These composites are fabricated as a sensor for high buildings or structures in locations where safety inspectors hardly access. There are some applications of stressluminescence powders by painting directly on concrete and pipe surface directly $[1,2]$. J.S. Kim et al. reported the use of stress-luminescence powders by spraying on alumina ceramics [3]. T. Nakanishi reported the fabrication of composite materials using both resin and stress-luminescence powder [4]. Stress-luminescent powers are difficult to use as itself because it is not easy to consolidate. So, we adopted the three-dimensional penetration casting (3DPC) process in Fig. 1 for fabricating composite. It can be expected that the $\mathrm{Al}$ composite of stress-luminescent can prevent failure of building and structure, or minimalize damages. Pure $\mathrm{Al}$ can be a good binder for composite material due to lightness, high ductility and low melting temperature compared to $\mathrm{Fe}, \mathrm{Cu}$, Ni.

\section{Experimental procedures}

\footnotetext{
a Corresponding author: matsuda@eng.u-toyama.ac.jp
}

Two kinds of commercial (a) stress-luminescence powders (Taikourozai Co.) and (b) EZ bright (EZ bright Cooperation) have respectively an average particle size of $\sim 7 \mu \mathrm{m}$ and $15 \mu \mathrm{m}$ as shown in Fig. 2(a), (b). Powders were prepared as preform and have shown emitting under black light in Fig. 2(c), (d). The $800^{\circ} \mathrm{C}$ molten $\mathrm{Al}$ prepared and poured into steel mould heated up to $750^{\circ} \mathrm{C}$. Then, the mould covered graphite cover for pressing molten Al. Press machine (4 tons of load) introduced pressure through graphite cover, and molten $\mathrm{Al}$ penetrated the preform powders. Mould after 3DPC process cooled down into chilly water. To observe microstructure, SEM was used. To estimate the stressluminescence, manual pressing machine was used.

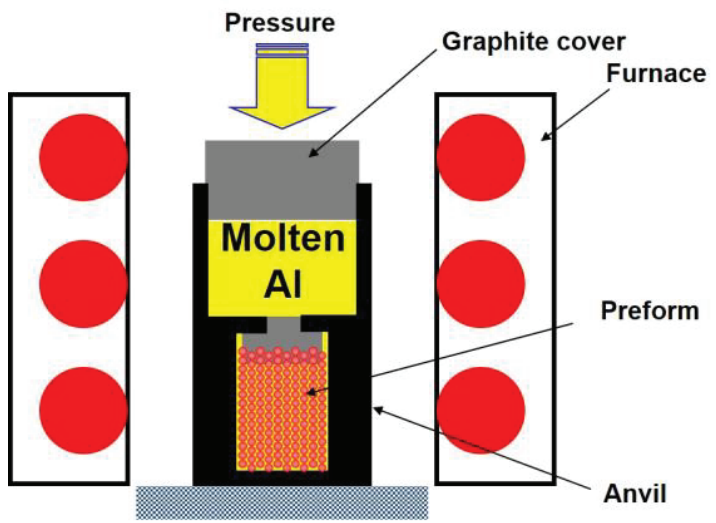

Figure 1. Schematic illustration of 3DPC facility. 


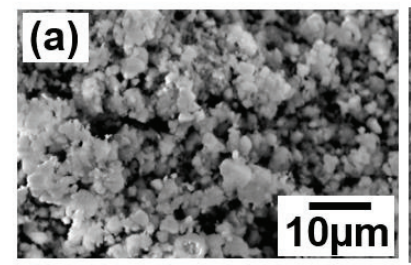

(c)

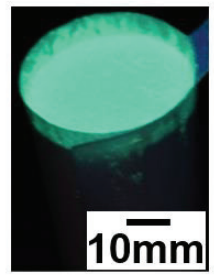

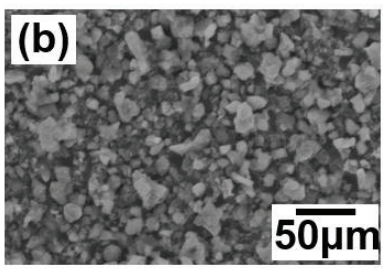

(d)

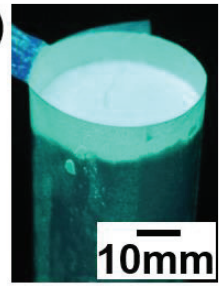

Figure 2. SEM images of (a) stress-luminescence powders (Taikourozai Co.), (b) EZ bright (EZ bright Cooperation), and (c), (d) preforms of powders, respectively.

\section{Results and discussion}
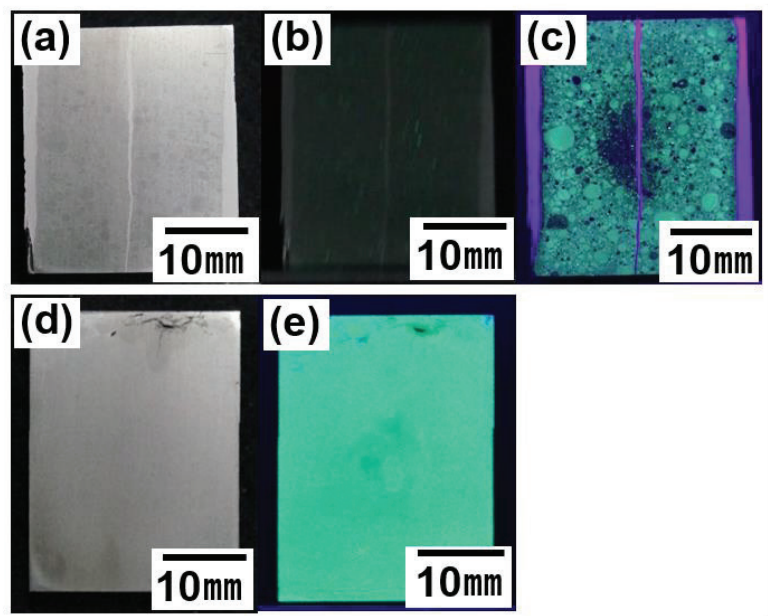

Figure 3. Cross sectional images of composite materials containing stress-luminescence powders (Taikourozai Co.) (a c); (a) under visible ray, (b) mechanical polished sample under black light, (c) electro-polished sample under black light; composite materials containing EZ bright (EZ bright Cooperation) (d,e); (d) under visible ray and (e) mechanical polished sample under black light.

Figure 3(a) shows cross sectional image of composite material fabricated using 3DPC process. White contrasts, both side and centre are $\mathrm{Al}$ in Fig $3(\mathrm{a} \sim \mathrm{c})$. With mechanical polishing, faint light emitted under black light. However, composite materials emitted strong light due to exposing more photo luminescence powders after electro polishing in Fig. 3(c). In the case of composite material with EZ bright powder, it emitted light under black light without electro polishing in Fig. 3(d, e). Figure 4 shows SEM-EDS analysis results. Powder size of both composite materisls after 3DPC process does not changed significantely. With EDS results, in Fig. 4 (a), smaller powder are well dispersed all over the composite materials, however, in the case of EZ bright, the boundaries between powder and Al matrx are clearly distinguished in Fig. 4(b).

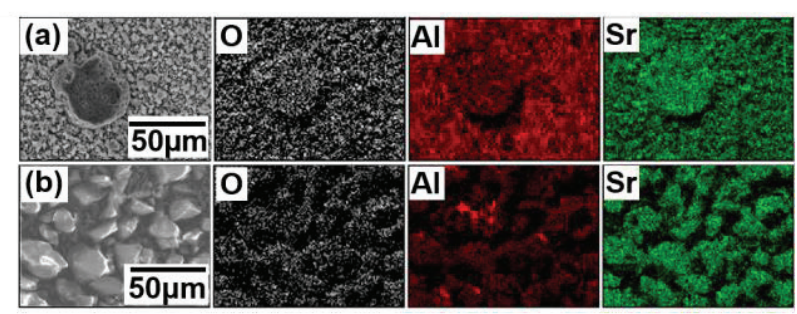

Figure 4. EDS analysis of both composite materials, (a) stressluminescence powders (Taikourozai Co.), (b) EZ bright (EZ bright Cooperation).
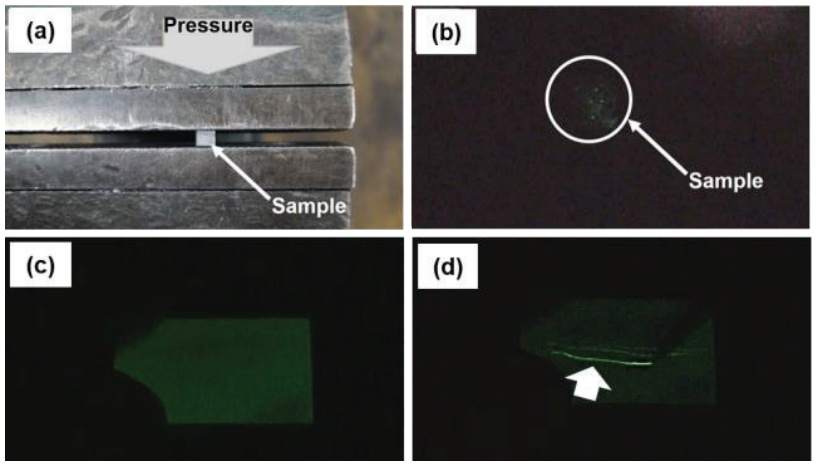

Figure 5. (a) appearance of stress-luminescence testing of stress-luminescence powders (Taikourozai Co.) using manual press machine, (b) emitting composite material under stress, (c) composite material with EZ bright (EZ bright Cooperation) under black light and (d) scratch test of (c).

Figure 5(a), (b) show stress-luminescence testing and result. 1 cubic centimetre $(1 \times 1 \times 1 \mathrm{~cm})$ sample was set between vice in manual pressing machine in Fig. 5(a). Then, compression stress applied to the sample, and sample started to emit under compression stress. Also, scratch test was conducted in Fig. 5 (c), (d). Before scratch testing, sample was exposed under black light for 5 min in Fig. 5(c), then, scratch test conducted without black light condition. It was possible to observe the emitting along scratch path marked with white arrow in Fig. 5 (d).

\section{Summary}

Al composites with stress-photo luminescent powders was fabricated by using 3DPC. After casting processing, powders maintained its stress luminescence property. That was confirmed using compression and scratch tests.

\section{References}

1. D. Ono, C.N. Xu, C. Li, N. Bu, J. JSEM 10 (2010) (written in Japanese)

2. Y. Kawabata, D. Ono, C. Li, E. Kawasaki, M. Iwanami, E. Kato, N. Ueno, C.N. Xu, J. JSEM 67 (2011) (written in Japanese)

3. J.S. Kim, Y.N. Kwon, N. Shin, K.S. Shon, Acta Mater 53 (2005) 
4. T. Nakanishi, J. Ceram. Soc. Japan 123 (2015) 